\title{
Hydrocarbons and renewable energy
}

To the editor:

Stephan Herrera's article "Industrial biotechnology - a chance at redemption" (Nat. Biotechnol. 22, 671-675, 2004) ends: "Without government prodding...this green dream won't have a happy ending. What a shame that would be." I disagree. It would not be a shame; it would be a failure.

Currently, we are moving to the summit of the mineral oil and natural gas economy. Oil and gas have proven much more efficient carbon-based raw materials than those used in previous epochs, such as coal and biomass. However, accessible reserves of oil and gas on earth are diminishing and greenhouse gas emissions are accumulating in the atmosphere, with potentially serious consequences for climate and weather, a prospect Herrera alludes to. Indeed, the United States Pentagon recently released a study outlining the possibility of 'abrupt' climate change ${ }^{1}$.

Although biotech holds promise in generating energy from renewable carbon sources, widespread adoption is likely only if 'green' approaches are more profitable than those using fossil fuels. This can be accomplished only if biochemical knowledge about biologically catalyzed processes is significantly broadened to enable the generation of products that influence the economies of industrialized nations. As yet, only a few examples exist.

Cargill (Minneapolis, MN, USA)-Dow's polylactide manufacturing process is one such example. But several other biological catalytic processes also have potential. In the microbially catalyzed biotransformation of carbohydrates to methane, for example, almost all of the energy of the sugar molecule can be conserved in the resulting methane molecules. Methane has the additional advantage that it separates voluntarily from the liquid reaction mixture. Moreover, many other organic substances can be converted correspondingly (e.g., fatty acids and amino acids). On the downside, cost factors remain in transport and storage of raw materials, use of sludge and purification of the methane gas. Microbial attack can be accelerated by supplementation of the reaction mixture with externally produced enzymes, which help to break down complex materials (e.g., polysaccharides and proteins or fats) into more tractable substrates.

More importantly, replacing oil products with biogenic organics containing more than one carbon atom remains more difficult.
Although easy to produce, ethanol's larger proportion of carbon and hydrogen (two carbon and six hydrogen atoms) to oxygen (one atom) compared with methane means only $65 \%$ of its molecular weight contributes to energy content. Energy yield from butanol is better-78\% contributes to energy-but homofermentative production has not yet been achieved; thus, yields from butanol fermentation remain lower than those from ethanol. Hydrocarbons offer $100 \%$ energy yield. Efficient pathways for their microbial production are not yet known.

The achievement of efficient energy generation from biomass under cost-effective conditions remains a key goal for industrial biotech. Thus, although Herrera is right to urge governments to realize their responsibility in funding industrial biotechnology, the onus is on biotechnologists to find the most efficient ways of deriving economically important products from complex renewable resources.

\section{Manfred Ringpfeil}

BIOPRACT GmbH, Mikrobielle Präparate, Biotechnologische Verfahren, Boden-und Gewässersanierung, Rudower Chaussee 29, entrance Kekuléstrasse 7, 12489 Berlin, Germany. e-mail:ringpfeil@biopract.de

1. Schwartz, P. \& Randall, D. Imagining the unthinkable an abrupt climate change scenario and its implications for United States national security. (Department of Defense, Washington, DC, 2003). http://www. ems.org/climate/pentagon_climate_change.html/

\section{AIDS, aneuploidy and oncogenes}

\section{To the editor:}

Your July issue contains an extraordinarily flawed review of a book that attempts to rehabilitate the scientific reputation of Peter Duesberg. The latter asserts that HIV is not the cause of AIDS. This is comparable to Lysenko convincing Stalin that acquired characteristics are inherited, which ruined a whole generation of Soviet agricultural science. Duesberg's theory of the noninfectious nature of HIV apparently convinced President Mbeki of South Africa, causing the loss of thousands and perhaps ultimately millions of lives.

In a paper in the Journal of Bioscience ${ }^{1}$, Duesberg provides a full compilation of his fallacies:

1. He claims AIDS is not contagious. Answer: It is clearly sexually transmitted from man to woman, from woman to man, from man to man and from contaminated needles. It is also transmitted from mothers to babies through mother's milk. It fills all of the requirements of Koch's postulates for infectious agents.

2. He asks why there is no HIV in most AIDS patients? Answer: AIDS patients effectively treated with combinations of antiHIV drugs can have HIV levels drop to below detectable levels, but levels always return to pretreatment levels when treatment is discontinued.

3. He asks why HIV would take 10 years from infection to AIDS? Answer: Because the tug of war between the virus and the immune system takes that long to be lost. The great menace of HIV is that it takes so long to kill that it provides catastrophic opportunities for the spread of disease. Epidemics like Ebola burn themselves out because they kill so quickly.

4. He says that AIDS is a chemical epidemic caused by anti-HIV drugs. Answer: How did the AIDS problem proliferate in the United States in the 1980s before there were any antiHIV drugs? And how did millions of HIV cases develop in sub-Saharan Africa before there were any HIV drugs in those areas?

One could go on and on in refuting Duesberg's misstatements about HIV, but there is no point. I will leave it to others to refute his claims about aneuploidy and cancer. I conclude by wondering how Nature Biotechnology found such a credulous reviewer as Miklos.

\section{Maxwell Gordon \\ 60 East End Avenue, \#22A, New York, NY 10028, USA.e-mail: Mgordon523@aol.com}

1. Duesberg, P. et al. J. Biosci. 28, 383-412 (2003).

\section{George Miklos responds:}

The very first serial analysis of gene expression (SAGE) data on colorectal cancer from Kinzler and Vogelstein's laboratory ${ }^{1}$ revealed that overexpression of oncogenes as the cause of human cancers could not be a generality. Subsequent microarray expression data on other solid tumors reinforce this finding, as do 